\title{
El pensar insumiso: intelectualidad y educación afrocolombiana en el siglo XX
}

\author{
José Antonio Caicedo-Ortiz* \\ Universidad del Cauca (Popayán, Cauca)
}

García-Rincón, Jorge Enrique (2016). Por fuera de la casa del amo: insumisión epistémica o cimarronismo intelectual en el pensamiento educativo afrocolombiano siglo XX. Pasto: Universidad de Nariño, $364 \mathrm{pp}$.

Desde el propio título, este libro incita a un candente debate, pues se trata de una metáfora que invita a reflexionar sobre aspectos como la autonomía, la agencia política, la insumisión y el cimarronismo epistémico, conceptos que simbolizan el sentido crítico y radical del pensamiento intelectual educativo afrocolombiano, foco de análisis de la presente obra. Se trata, además, de un accionar que se ha llevado a cabo por fuera o al margen de los linderos del poder estatal e institucional, según el autor. Y digo que es un debate incitador, sobre todo, porque interpela las posiciones que han privilegiado la perspectiva integracionista de la agencia política afrocolombiana, toda vez que propone que el campo educativo afrocolombiano es un proceso construido desde su propia experiencia, relaciones y capacidad para actuar sin los tutelajes del poder.

El libro de García-Rincón se suma a una estela de investigaciones que, en los últimos diez años, ha venido configurando un campo de estudios relacionado con el análisis del pensamiento y las trayectorias de la intelectualidad afrocolombiana en el siglo XX (Arboleda-Quiñónez, 2016; Caicedo-Ortiz, 2013; Valderrama, 2014;

\footnotetext{
* Magíster en Estudios Latinoamericanos de la Universidad Andina Simón Bolívar (Ecuador) y sociólogo de la Universidad del Valle (Colombia). Profesor del Departamento de Estudios Interculturales de la Universidad del Cauca. Coordinador de la Cátedra Afrocolombiana Rogerio Velásquez Murillo.Correo electrónico: joseortiz@unicauca.edu.co
} 
Valencia-Angulo, 2019) y el cual tiene como objetivo común resaltar el papel de los y las afrocolombianas como productores de conocimiento. García-Rincón nos presenta un estudio profundo y riguroso sobre la tradición intelectual educativa, una adjetivación que conlleva a pensar la autonomía propia de este campo y que contribuye de tal modo a ampliar la compleja y heterogénea gama de esta tradición intelectual.

Por fuera de la casa del amo: insumisión epistémica o cimarronismo intelectual en el pensamiento educativo afrocolombiano siglo $X X$ tiene como argumento central la existencia de un pensamiento educativo producido por hombres y mujeres que, desde distintas posiciones de sujeto, han contribuido a su configuración. A partir del análisis de textos, procesos y biografías de pensadores y pensadoras afrocolombianas (escritores, ensayistas, investigadores), el autor organiza el extenso y disperso archivo de la diáspora intelectual a través de la cual se constata la trayectoria de un pensamiento educativo afrocolombiano, cuyos rasgos esenciales son la insumisión y el cimarronismo epistémico. Este último concepto, según García-Rincón, "implica un pensamiento situado en el carácter permanente de la colonización de los pueblos de origen africano en América y en el mundo; es decir, la insumisión epistémica se entiende aquí como el pensamiento afro que confronta, critica y subvierte el proyecto colonizador europeo-occidental y la escritura académica que lo sostiene" (14). En otras palabras, el rasgo fundamental de este pensamiento es su carácter anticolonial.

Acto seguido, vincula la tradición de la intelectualidad afrodiaspórica anterior con el movimiento social afrocolombiano de finales de la década del noventa del siglo XX, con líderes y lideresas comunitarias surgidas en esta etapa de Estado multicultural, a fin de visibilizar las formas de producción colectiva de conocimientos. Por lo tanto, considero que se trata de un excelente ejercicio de artesanía intelectual, mediante el cual el autor arma el rompecabezas de la tradición intelectual educativa afrocolombiana. Como lo señala él mismo:

\footnotetext{
(...) la producción teórica de los intelectuales mencionados en materia educativa y las experiencias educativas del movimiento social afro (...) conforman el objeto central de este trabajo, desde un enfoque hermenéutico nos hemos preguntado por los elementos claves que permiten comprender el sentido crítico-político, en términos de libertad, autonomía y dignidad, presentes en el pensamiento educativo afrocolombiano del siglo XX. (22)
}

Por ende, la tesis central de García-Rincón corresponde a un pensamiento autónomo gestado al margen de los centros de poder epistémicos, políticos y gubernamentales que legitiman sus dinámicas de saber/poder, al tiempo que excluyen los pensamientos situados al borde de su hegemonía. 
En cuatro capítulos, organizados de forma coherente, se desenvuelve la tesis que acabo de señalar. El primer capítulo, "De la invisibilidad epistémica a la insumisión del negro en Colombia", resalta el proceso y las experiencias organizativas que iniciaron el camino por la visibilidad de un pensamiento crítico educativo que tiene en la identidad étnica, territorial y cultural su foco de producción y acción. El segundo capítulo, "Pensamiento educativo afrocolombiano. Los precursores del siglo XX", visibiliza a quienes, desde diversos campos de producción como la literatura, las ciencias sociales, los estudios folclóricos, el periodismo, entre otros, dejaron sendas reflexiones sobre asuntos relacionados con la educación, a través de la ficción literaria como en el caso de Manuel Zapata-Olivella y Miguel A. Caicedo; la investigación académica con Rogerio Velásquez-Murillo y el discurso político en la figura de Diego Luis Córdoba. El tercer capítulo, "Las experiencias educativas del movimiento social afrocolombiano", da un salto de las voces individuales o de autor, rasgo vital de los pioneros, a las voces colectivas por medio de las experiencias etnoeducativas surgidas del movimiento social afrocolombiano (Casita de Niños, colegio comunitario de Villapaz, Palenke de San Basilio, La Playa de Francisco Pizarro y Buenaventura) y la manera como estas han influido en la educación oficial. El último capítulo, "La ampliación del campo epistémico en el pensamiento educativo afrocolombiano: otros pensadores y eventos del movimiento social", nos lleva por la senda del reconocimiento de autores que han tenido menos visibilidad dentro de la tradición intelectual, tales como Amir Smith Córdoba, Jesús Lácides Mosquera y Juan de Dios Mosquera, los cuales representan, en la visión del autor, el debate más radical sobre la necesidad de una educación propia y descolonizadora en contra del racismo en el sistema educativo.

Sin lugar a dudas, este libro es un gran aporte al campo de estudios sobre la intelectualidad afrocolombiana. Su rigor analítico, el aporte a través de las categorías centrales, así como su vasto desarrollo hermenéutico, contribuyen a delinear un campo de reflexión necesario para la academia colombiana y para los propios investigadores e investigadoras afrocolombianas. El asunto esencial es la disputa por el control epistémico y la necesidad de visibilizar la existencia de una tradición intelectual que, en el siglo XX, ha dejado un legado fundamental para comprender desde la propia voz del sujeto afro, sus visiones, aspiraciones y autorrepresentaciones y la manera como los asuntos de la raza se articulan al debate nacional.

Por consiguiente, se trata de un pensamiento que devela una concepción de educación casa adentro, parafraseando al intelectual afroecuatoriano Juan García (1983), la cual resalta la continuidad histórica del cimarronismo y el sentido libertario como proyecto epistémico, agenciado desde los tiempos de las fugas antiesclavis- 
tas, pasando por la apropiación del discurso ilustrado en el siglo XX hasta la acción colectiva afrocolombiana en el contexto del Estado multicultural.

Finalmente, esta intelectualidad que García-Rincón analiza tiene como centro de debate el campo educativo y etnoeducativo, otro de los temas pocos desarrollados en los estudios afrocolombianos. Este libro es una vorágine de ideas bien construidas que invita a reflexionar sobre el papel que la intelectualidad afrocolombiana ha tenido en el contexto educativo; como lo sugiere el mismo autor, es una manera de pensar de forma insumisa y por fuera de la casa del amo.

\section{Referencias}

Arboleda-Quiñonez, Santiago (2016). Le han florecido nuevas estrellas al cielo. Suficiencias intimas y clandestinización del pensamiento afrocolombiano. Cali: Poemia.

Caicedo-Ortiz, José Antonio (2013). A mano alzada... memoria escrita de la diáspora intelectual afrocolombiana. Popayán: Sentipensar.

García, Juan (1983). La tradición oral: una herramienta para la etnoeducación. Una propuesta de las comunidades de origen africano para aprender casa adentro. Quito: Fedoca.

Valderrama, Carlos A. (2014). Black Politics of Folklore: Expanding the Sites and Forms of Politics in Colombia (Tesis de maestría). Recuperado de https://scholarworks.umass.edu/cgi/ viewcontent.cgi article $=1000 \&$ context $=$ masters_theses_2

Valencia-Angulo, Luis Ernesto (2019). Negro y afro. La invención de dos formas discursivas. Cali: Universidad Icesi. 